\title{
Sistem Pendukung Keputusan Pemilihan Ketua Badan Eksekutif Mahasiswa Dengan Metode Simple Additive Weighting
}

\author{
Agung Kharisma Hidayah ${ }^{1}$, Yetman Erwadi ${ }^{2}$ \\ ${ }^{1}$ Program Studi Teknik Informatika, Fakultas Teknik, Universitas Muhammadiyah Bengkulu \\ ${ }^{2}$ Program Studi Sistem Informasi, Fakultas Teknik, Universitas Muhammadiyah Bengkulu
}

\begin{abstract}
Jl. Bali, Bengkulu 38119
kharisma@umb.ac.id ${ }^{1}$

yetman@umb.ac.id ${ }^{2}$
\end{abstract}

\begin{abstract}
At each College there is always a Student Organization named Student Executive Board headed by a chairman and other officials. In the conclave, there is often a shortage of candidates for chairman of the Executive Board assessment Students are still done manually. That is the background of the author makes this application to assist voters in determining appropriate candidates for chairman, formulation of the problem in this research is how the weighting Addetive Simple method (SAW) can be used in a Decision Support System applications conclave Student Executive Board with a case study at the University of Muhammadiyah Bengkulu. That discussions do not stray problem, then there are some restrictions are made, namely: application decision support system is made on the basis of Simple Additive Weighting (SAW), which created a system of decision support, so that the real decisions were taken remain on the students as voters, Criteria used in the study to adjust the internal University, as well as data used in this study is data in 2014-2015.Tujuan this study is to produce a softwere Decision Support Systems (DSS) election of the chairman of the Student Executive Board with Simple Additive weighting method (SAW), case studies at the University of Muhammadiyah Bengkulu. This research was carried out independently, not bound by the agency or any party. This study was carried on at the Muhammadiyah University of Bengkulu in April and May 2015. The data collection method used is literature study, field study and observation. The study produced a Keputuan Support System Chief Executive Board of the Student Selection by application of simple additive weighting method is running optimally .
\end{abstract}

\begin{abstract}
Abstrak - Pada setiap Perguruan Tinggi selalu ada Organisasi Kemahasiswaan yang diberi nama Badan Eksekutif mahasiswa yang dipimpin oleh seorang ketua dan pengurus lainnya. Dalam pemilihan ketua, seringkali terjadi kekurangan karena penilaian calon ketua Badan Eksekutif Mahasiswa yang masih dilakukan secara manual. Itulah yang melatarbelakangi penulis membuat aplikasi ini untuk membantu pemilih dalam menentukan calon ketua yang tepat, Rumusan masalah pada penelitian ini adalah bagaimana metode Simple Addetive Weighting (SAW) dapat digunakan pada sebuah aplikasi Sistem Pendukung Keputusan pemilihan ketua Badan Eksekutif Mahasiswa dengan studi kasus di Universitas Muhammadiyah Bengkulu. Agar pembahasan masalah tidak menyimpang, maka ada beberapa batasan yang dibuat, yaitu: Aplikasi sistem pendukung keputusan dibuat dengan berbasiskan Simple Additive Weighting (SAW), Sistem yang dibuat merupakan pendukung keputusan saja, sehingga keputusan sesungguhnya yang diambil tetap berada pada mahasiswa sebagai pemilih, Kriteria yang digunakan dalam penelitian menyesuaikan dengan internal Universitas, serta data yang digunakan pada penelitian ini adalah data tahun 2014-2015.Tujuan penelitian ini adalah menghasilkan sebuah softwere Sistem Pendukung Keputusan (SPK) pemilihan ketua Badan Eksekutif Mahasiswa dengan metode Simple Additive Weighting (SAW), studi kasus di Universitas Muhammadiyah Bengkulu. Penelitian ini dilaksanakan secara mandiri, tidak terikat oleh instansi atau pihak manapun. Penelitian ini di laksanakan di Universitas Muhammadiyah Bengkulu pada bulan april dan mei 2015. Adapun metode pengumpulan data yang digunakan adalah study literatur, studi lapangan dan observasi. Penelitian ini menghasilkan suatu Sistem Pendukung Keputuan Pemilihan Ketua Badan Eksekutif Mahasiswa dengan penerapan metode simple additive weighting yang berjalan dengan optimal.
\end{abstract}

\section{Pendahuluan}

Badan Eksekutif Mahasiswa (BEM) merupakan organisasi kemahasiswaan intrakampus yang berkedudukan sebagai badan eksekutif dalam tiap tingkatan yaitu tingkat universitas dan tingkat fakultas [5]. Setiap organisasi tentu memiliki pengurus yang bertugas mengatur jalannya roda organisasi. Selanjutnya menurut Khairil, Badan Eksekutif Mahasiswa dalam menjalankan organisasi dipimpin oleh satu orang ketua umum dan wakil ketua umum yang dipilih secara demokratis dan diberi wewenang untuk menyusun komposisi pimpinan dan kelengkapan organisasi [5].

Selayaknya sebuah organisasi, Badan Eksekutif Mahasiswa tentu memiliki masa jabatan dalam kepengurusannya. Masa jabatan ketua umum Badan Eksekutif Mahasiswa adalah 1 (satu) tahun, 
dan sesudahnya tidak dapat dipilih kembali. Ketua BEM dipilih oleh seluruh mahasiswa aktif yang terdaftar di universitas atau institut. Pemilihan ketua BEM ini masih mendapat kendala dalam prosesnya, karena seringkali mahasiswa tidak dapat menilai calon ketua BEM yang tepat dengan memenuhi kriteria-kriteria yang ada. Mahasiswa mendapat kendala dalam memutuskan calon ketua BEM yang diprioritaskan. Kendala yang dihadapi adalah mahasiswa sebagai pemilih tidak menggunakan metode yang dapat menangani permasalahan prioritas dengan banyak kriteria.

Aplikasi ini akan dibuat menggunakan metode Simple Additive Weighting karena metode ini merupakan metode yang paling dikenal dan paling banyak digunakan orang dalam menghadapi situasi MADM [1]. SAW (Simple Additive Weighting) merupakan metode yang menyeleksi alternatif terbaik dari sejumlah alternatif berdasarkan kriteria-kriteria yang ditentukan dengan melakukan perankingan untuk mengetahui nilai tertinggi sampai terendah [4]. Salah satu contoh penerapan metode SAW adalah pada tugas skripsi yang disusun oleh Ariyanto dengan judul "Sistem Pendukung Keputusan pemilihan karyawan terbaik dengan metode SAW (Simple Additive Weighting) (studi kasus di Pamella Swalayan)

\section{Landasan Teori}

A. Sistem Pengambilan Keputusan

Sistem pengambilan keputusan adalah alat bantu bagi pengambilan keputusan manajerial, tetapi pengambilan keputusan memiliki beragam konteks yang berbeda dimana tidak semua pengambilan keputusan adalah bergantung dan memuaskan hanya kepada satu pihak [3].

Secara umum sistem pendukung keputusan didefinisikan sebagai bagian dari sistem informasi berbasis komputer termasuk sistem berbasis pengetahuan atau manajemen pengetahuan yang dipakai untukmendukung pengambilan keputusan dalam suatu organisasi atau perusahaan.

Dimana Sistem Pendukung Keputusan ini adalahbagian dari Sistem Informasi berbasis komputer, termasuk didalamnya sistem berbasis pengetahuan yang dipakai untuk mendukung pengambilan keputusan dalam suatu organisasi perusahaan.

\section{B. Komponen Sistem Pendukung Keutusan}

Komponen-kompones sistem pendukung keputusan terdiri dari data management system, model management system, knowledge base, user interface, serta user [6].

\section{Data Management System}

Segala aktifitas yang berhubungan dengan pengambilan, penyimpanan dan pengaturan data-data yang relevan dengan konteks keputusan yang akan diambil. Selain itu, komponen ini juga menyediakan berbagai fungsi keamanan, prosedur integritas data, dan administrasi data secara umum yang berkaitan dengan SPK. Berbagai tugas ini dilakukan dalam data management system beserta beberapa sub systemnya.

\section{Model Management System}

Sistem ini menampilkan aktivitas pengambilan, penyimpanan dan pengaturan data dengan berbagai model kuantitatif yang menyediakan kemampuan analitis untuk SPK.

\section{Knowledge Base}

Aktivitas yang berkaitan dengan pengenalan masalah, dan menghasilkan solusi final maupun sementara, hal-hal yang berkaitan dengan manajemen proses pemecahan masalah merupakan inti dari komponen ini. Knowledge base merupakan "otak" dari kelima komponen SPK. Data dan model diolah untuk kemudian hasilnya menjadi bahan pertimbangan bagi user dalam mengambil keputusan.

\section{UserInterface}

Merupakan jalir penghubung antara sistem dengan user, sehingga komposen-komponen sistem SPK dapat diakses dan dimanipulasi dengan mudah oleh user untuk memberikan dukungan pada pengambilan keputusan. Kemudahan penggunaan dan komunikasi antar user dan SPK pada dasarnya merupakan ukuran keberhasilan penggunaan SPK itu sendiri.

\section{User}

Desain, implementasi dan pemanfaatan SPK tidak akan ffektif jika tidak disertai eran pengguna. Kemampuan, keteramplan, motivasi, dan pengetahuan pengguna sebagai pengatur SPK, akan menentukan efektivitas dari pengguanaan SPK

C. Fuzzy Multiple Attribute Decision Making (FMADM)

Fuzzy MADM adalah suatu metode yang digunakan untuk mencari alternatif optimal dari sejumlah alternatif dengan kriteria tertentu [2].

Ada beberapa metode yang dapat digunakan untuk menyelesaikan masalah Fuzzy MADM (Handayani dkk, 2013) antara lain:
1. Simple Addictive Weighting Method (SAW)
2. Weighted Product (WP) 


\section{Elimination Et Choix la Reaalite(ELECTRE) \\ 4. Technique for Order Preference by Similiarity to Ideal Solution (TOPSIS) \\ 5. Analytic Hierarchy Process (AHP)}

D. Metode Penyelesaian Fuzzy Multiple Attribute Decision Making (FMADM) dengan Simple Addictive Weighting Method $(S A W)$

Metode ini merupakan metode yang paling dikenal dan paling banyak digunakan orang dalam menghadapi situasi MADM [1]. SAW (Simple Additive Weighting) merupakan metode yang menyeleksi alternatif terbaik dari sejumlah alternatif berdasarkan kriteria-kriteria yang ditentukan dengan melakukan perankingan untuk mengetahui nilai tertinggi sampai terendah [4]. Menurut Basyaib, metode ini mengharuskan pembuat keputusan menentukan bobot bagi setiap atribut [1]. Skor total untuk sebuah alternatif diperoleh dengan menjumlahkan seluruh hasil perkalian antara rating (yang dapat dibandingkan lintas atribut). Lanjutnya rating setiap atribut haruslah bebas dimensi dalam arti telah melewati proses normalisasi sebelumnya..

\section{Metode Penelitian}

Model Pengembangan sistem ini menggunakan model incremental

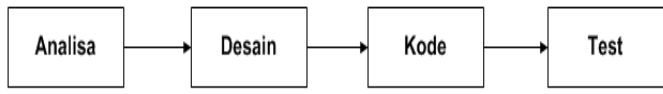

Gbr 1. Model Incremental

A. Analisa Data

Pada penelitian penulis menggunakan teknik pengumpulan data dengan wawancara, observasi dan studi pustaka untuk mendapatkan data-data dalam penelitian

B. Desain Sistem

Desain sistem menggunakan

1. Data Flow Diagram

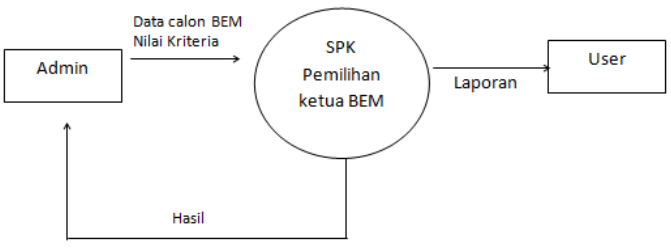

Gbr 2. Data Flow Diagram

2. Entity Relationship Diagram

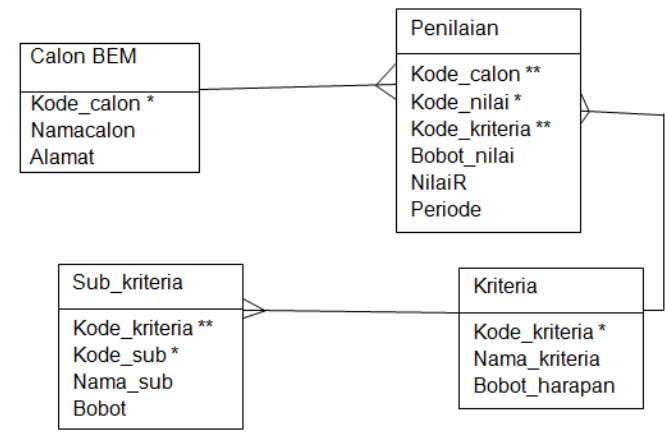

Gbr 3. Entity Realtionship Diagram

\section{Hasil dan Pembahasan}

A. Hasil

Adapun tampilan menu utama Sistem Penukung Keputusan Pemilihan Ketua Badan Eksekutif Mahasiswa adalah sebagai berikut :

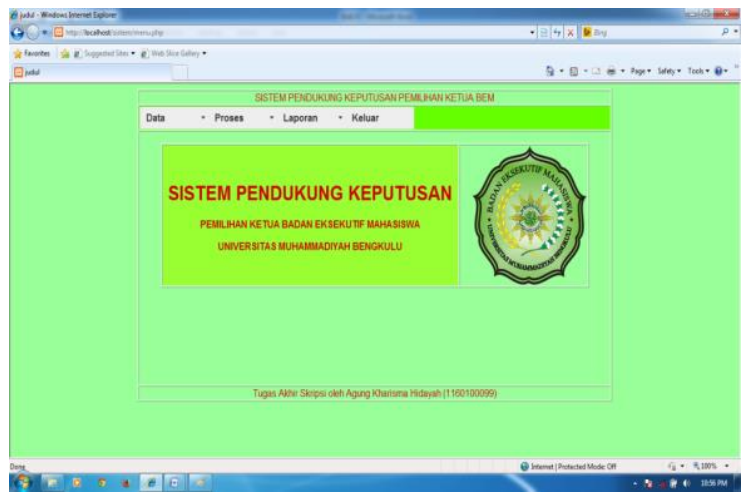

Gbr 4. Menu Utama

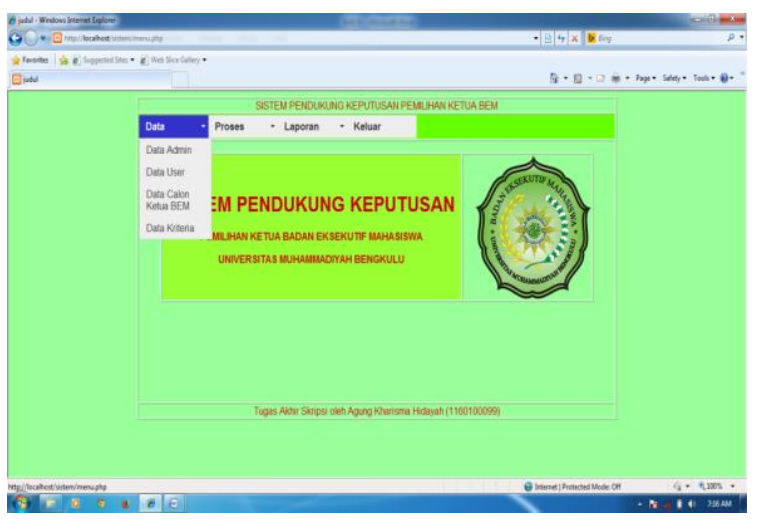

Gbr 5. Tampilan menu Data

Menu data berfungsi untuk menampilkan data admin, data user, calon ketua BEM dan data kriteria. Pada setiap data yang terdapat pada menu data, admin bisa melakukan proses penambahan record data baru, mengoreksi data yang sudah ada, menghapus data serta melakukan proses pencarian dengan cara mengklik tombol-tombol yang tersedia pada setiap sub menu nya. 


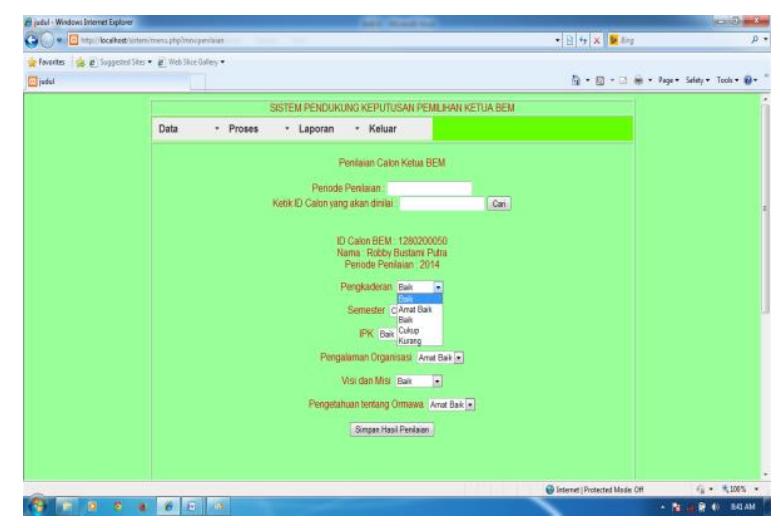

Gbr 6. Tampilan menu Proses

Pada menu proses dilakukannya penilaian dan perhitungan saw untuk menentukan calon ketua BEM yang memperoleh nilai terbaik

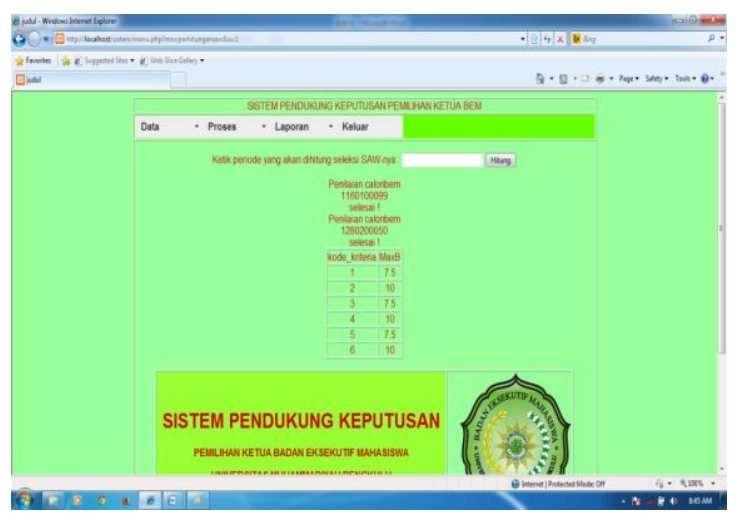

Gbr 7. Tampilan menu Perhitungan

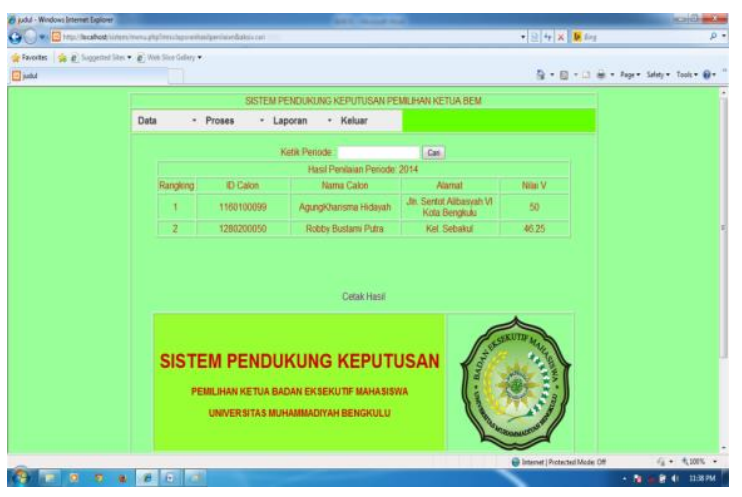

Gbr 8. Tampilan menu Laporan

Adapun menu laporan berisi laporan hasil penilaian dan perhitungan saw terhadap calon ketua BEM yang telah didata

\section{B. Pembahasan}

Menurut Indrawaty, Andriana \& Prasetya metode SAW membutuhkan proses normalisasi matriks keputusan (X) ke suatu skala yang dapat diperbandingkan dengan semua rating alternatif yang ada [4].

$$
r_{i j}=\left\{\begin{array}{cc}
\frac{x_{i j}}{M a x x_{i j}} & \text { Jika jatribut keuntungan (benefit) } \\
i & \\
\operatorname{Min} x_{i j} & \\
\frac{i}{x_{i j}} & \text { Jika jatribut biaya (cost) }
\end{array}\right.
$$

Keterangan:

$\mathrm{Rij}=$ nilai rating kinerja normalisasi

$\mathrm{Xij}=$ nilai atribut yang dimiliki dari setiap criteria

Max xij = nilai terbesar dari setiap kriteria

Min xij = nilai terkecil dari setiap kriteria

Benefit $=$ nilai terbesar adalah terbaik

Cost $=$ nilai terkeciladalah terbaik

Dimana rij adalah rating kinerja ternormalisasi dari alternatif $\mathrm{Ai}$ pada atribut $\mathrm{Cj} ; \mathrm{i}=1,2, \ldots . \mathrm{m}$ dan $\mathrm{j}=1,2, \ldots, \mathrm{n}$.

Nilai preferensi untuk setiap alternatif (V1) diberikan sebagai:

$$
V_{i}=\sum_{j=1}^{n} w_{j} r_{i j}
$$

Keterangan:

$\mathrm{Vi}=$ rangking untuk setiap alternatif

$\mathrm{Wj}=$ nilai bobot dari setiap kriteria

$\mathrm{Rij}=$ nilai rating kinerja ternormalisasi

Nilai Vi yang lebih besar mengindikasibahwa alternatif Ai lebih terpilih.

Metode SAW melakukan tahapan dalam aplikasinya, yaitu sebagai berikut :

1. Perbandingan lintas atribut sehingga hasil penelitian tersebut harus tidak berdimensi dengan jalan melakukan normalisasi linier;

2. Dilakukan perkalian diantara bobot tiap atributdengan hasil penilaian bebas dimensi tersebut;

3. Hasil perkalian tersebut dijumlahkan untuk tiap bobot;

Dipilih alternatf yang memiliki nilai tota perkalian terbesar sebagai kandidat terbaik

\section{Kesimpulan dan Saran}

A. Kesimpulan

Dari keseluruhan penulisan ini, maka dapat diambil kesimpulan sebagai berikut :

1. Penelitian ini menghasilkan suatu aplikasi Sistem Pendukung Keputusan Pemilihan Ketua Badan Eksekutif Mahasiswa dengan Metode Simple Additive Weighting.

95 | http://www.jurnal.umb.ac.id/index.php/JSAI 
2. Memberikan rekomendasi dalam pengambilan keputusan untuk menentukan ketua Badan Eksekutif Mahasiswa yang diseleksi secara objektif.

3. Menambah khasanah pengetahuan tentang kecerdasan buatan, khususnya berhubungan dengan aplikasi Sistem Pendukung Keputusan (SPK) yang menggunakan metode Simple Additive Weighting (SAW);

B. Saran

Untuk pengembangan aplikasi ini agar lebih baik lagi, diharapkan bisa dikembangkan dengan menggunakan bahasa pemrograman yang berbeda ataupun metode yang berbeda.

\section{Referensi}

[1] Basyaib, Fachmi. 2006. Teori Pembuatan Keputusan. Jakarta: Grasindo.

[2] Handayani, Tri., Leksito, Wawan \& Susyanto, Teguh. 2013. Sistem Pendukung Keputusan beasiswa diklat dengan Fuzzy MADM. 23384018

[3] Ilhamsyah. 2014. Sistem Pendukung Keputusan untuk menyeleksi calon siswa Sekolah Menengah Kejuruan (SMK) Dwi Tunggal Tanjung Morawa menggunakan model Multi-Attribute Decission Making (MADM) dengan metode Simple Additive Weighting (SAW). 2301-9425

[4] Indrawaty, Youllia., Andriana \& Prasetya, R.A. 2011. Implementasi metode Simple Additive Weighting pada Sistem engambilan Keputusan sertifikasi guru. Bandung: Institut Teknologi Bandung.

[5] Khairil. 2011. Pedoman Umum Organisasi Kemahasiswaan. Bengkulu: Universitas Muhammadiyah bengkulu.

[6] Ramdani, Irpan. 2012. Komponen-komponen Sistem Pendukung Keputusan (On-line) Available athttp://irpantips4u.blogspot.com/2012/11/ko mponen- komponen-sistem-pendukung.html. (diakses 11 februari 2015) 